\title{
PENERAPAN ISSU TERKAIT KESELAMATAN PASIEN
}

\author{
Try Ayu Amanda Pasaribu \\ tryayuamanda08@gmail.com
}

\section{LATAR BELAKANG}

Keselamatan Pasien adalah suatu sistem yang membuat asuhan keperawatan terhadap pasien menjadi lebih aman. Perawat merupakan salah satu sumber daya manusia yang sangat dibutuhkan untuk mencapai kinerja yang optimal. Keselamatan menjadi isu global dan terangkum dalam lima isu penting yang terkait di rumah sakit yaitu keselamatan pasien, keselamatan pekerja atau petugas kesehatan, keselamatan bangunan dan peralatan di rumah sakit, keselamatan lingkungan dan keselamatan bisnis rumah sakit yang terkait dengan kelangsungan hidup rumah sakit. Mengingat masalah keselamatan pasien merupakan masalah yang perlu ditangani segera maka diperlukan standar keselamatan pasien fasilitas pelayanan kesehatan yang merupakan acuan untuk melaksanakan kegiatannya. Berdasarkan Permenkes RI Nomor 11 Tahun 2017 tentang Keselamatan Pasien bahwa setiap fasilitas pelayanan kesehatan harus menyelenggarakan keselamatan pasien. Keselamatan pasien merupakan prioritas utama untuk dilaksanakan terkait dengan isu mutu dan Citra perumahsakitan. Gerakan (Patient Safety) keselamatan pasien telah menjadi spirit dalam pelayanan rumah sakit seluruh dunia tidak hanya rumah sakit di negara maju yang menerapkan keselamatan pasien untuk menjamin mutu pelayanan, tetapi juga rumah sakit di negara berkembang seperti di Indonesia. Kementerian Kesehatan Republik Indonesia telah mengeluarkan Peraturan Menteri Kesehatan No. 11 Tahun 2017 tentang keselamatan pasien di rumah sakit. Peraturan ini menjadi tonggak utama operasionalisasi keselamatan pasien di rumah sakit seluruh Indonesia. Banyak rumah sakit di Indonesia yang telah berupaya membangun dan mengembangkan keselamatan pasien, namun upaya tersebut dilaksanakan berdasarkan pemahaman manajemen terhadap keselamatan pasien.

Keselamatan pasien merupakan persoalan kritis dalam rumah sakit yang sering dipublikasikan dan menjadi fokus Internasional. Keselamatan pasien menjadi standar kebijakan dalam organisasi akreditasi Internasional. Komite akreditasi Rumah Sakit telah menyusun standar keselamatan pasien rumah sakit dalam instrumen standar keselamatan pasien rumah sakit untuk meningkatkan mutu pelayanan pasien dan menjamin keselamatan pasien. Komite yang berperan dalam keselamatan pasien adalah komite peningkatan mutu dan 
keselamatan pasien yang menjangkau ke seluruh unit kerja di rumah sakit. Penerapan manajemen keselamatan pasien di rumah sakit memegang peranan yang sangat penting dalam upaya mencegah atau meminimalkan terjadinya insiden keselamatan pasien yang bersifat merugikan. Keselamatan pasien merupakan tanggung jawab semua pihak yang berkaitan dengan pemberi pelayanan kesehatan. Rumah sakit adalah institusi pelayanan kesehatan bagi masyarakat dengan karakteristik tersendiri yang dipengaruhi oleh perkembangan ilmu pengetahuan kesehatan, kemajuan teknologi, dan kehidupan sosial ekonomi masyarakat yang harus tetap mampu meningkatkan pelayanan yang lebih bermutu dan terjangkau oleh masyarakat agar terwujud derajat kesehatan yang setinggi-tingginya, seperti yang dijelaskan dalam Undang-undang Rumah Sakit Nomor 44 Tahun 2009 bahwa Rumah Sakit wajib melaksanakan pelayanan kesehatan yang aman, bermutu, anti diskriminasi dan efektif, dengan mengutamakan kepentingan pasien.

\section{METODE}

Metode yang digunakan pada kajian ini adalah dengan menganalisis dari berbagai sumber bacaan. Referensi yang saya ambil dari jurnal online dan tesis dengan pengerjaannya dengan cara membandingkan artikel satu dengan artikel yang lain.

Metode yang digunakan pengkajian ini dengan mengumpulkan informasi dari berbagai referensi termasuk di dalamnya hasil-hasil penelitian.

\section{HASIL}

Hasil dari pengkajian ini Keselamatan Pasien adalah suatu sistem yang membuat asuhan pasien lebih aman, meliputi assessment risiko, Identifikasi dan pengelolaan risiko pasien, pelaporan dan analisis insiden, kemampuan belajar dari insiden dan tindak lanjutnya, serta implementasi solusi untuk meminimalkan timbulnya risiko dan pencegah terjadinya Cedera yang disebabkan oleh kesalahan akibat melaksanakan suatu tindakan atau tidak mengambil tindakan yang seharusnya diambil.

Rumah sakit sebagaiinstansi pelayanan kesehatan yang berhubungan langsung dengan pasien harus mengutamakan pelayanan kesehatan yang aman, bermutu, anti diskriminasi dan efektif dengan mengutamakan kepentingan pasien sesuai dengan standar pelayanan rumah sakit. Pasien sebagai pengguna pelayanan kesehatan berhak memperoleh keamanan dan keselamatan dirinya selama dalam perawatan di rumah sakit. Perkembangan rumah sakit saat ini telah mengalami transformasi. Industri Rumah Sakit mengalami perkembangan cukup besar 
seiring diterbitkannya berbagai peraturan dan perundang-undangan yang mendukung iklim investasi dan menciptakan kondisi bisnis dan jasa rumah sakit yang lebih baik.

Isu penting terkait keselamatan di rumah sakit (RS) yaitu : keselamatan pasien, keselamatan pekerja atau petugas kesehatan, keselamatan bangunan dan peralatan di RS yang berdampak terhadap keselamatan pasien dan petugas, keselamatan lingkungan yang berdampak terhadap pencemaran lingkungan, dan keselamatan "bisnis" RS terkait dengan kelangsungan hidup RS. Patient Safety merupakan istilah yang saat ini cukup populer dalam pelayanan kesehatan. Patient Safety merupakan upaya upaya pelayanan yang mengutamakan pada keselamatan pasien. Keselamatan pasien adalah suatu sistem dimana rumah sakit membuat asuhan pasien lebih aman, mencegah terjadinya Cedera yang disebabkan oleh kesalahan akibat melaksanakan suatu tindakan atau tidak mengambil tindakan yang seharusnya diambil. Isu Keselamatan (safety) di era global saat ini menjadi pusat perhatian dunia di berbagai sektor, termasuk di sektor kesehatan. Isu Keselamatan di sektor kesehatan terkait dengan Rumah Sakit salah satunya adalah keselamatan pasien. Terdapat berbagai macam obat, tes dan prosedur, alat dengan teknologinya, bermacam jenis tenaga profesi dan non profesi di rumah sakit yang siap memberikan pelayanan kepada pasien selama 24 jam. Keberagaman dan kerutinan pelayanan tersebut apabila tidak dikelola dengan baik dapat menghasilkan kejadian tidak diharapkan (KTD).

Keselamatan merupakan prinsip dasar dalam pelayanan pasien dan komponen kritis dari manajemen mutu. Keselamatan pasien adalah sebuah transformasi budaya, di mana budaya yang diharapkan adalah budaya keselamatan, budaya tidak menyalahkan, budaya lapor dan budaya belajar. Keselamatan pasien merupakan isu global dan komponen penting dari mutu layanan kesehatan, prinsip dasar dari pelayanan pasien dan komponen kritis dari manajemen mutu. Di Indonesia, program keselamatan pasien dicanangkan pada tahun 2005, dan terus berkembang menjadi isu utama dalam pelayanan medis di Indonesia. Konsep Patient Center Care (PCC) merupakan paradigma baru dalam pelayanan kesehatan kepada pasien, di mana pemberian pelayanan berfokus kepada pasien, Yang intinya adalah pelayanan kesehatan yang diberikan harus berkualitas dan aman (safety) dengan memperhatikan kebutuhan dan nilai-nilai pasien. Budaya keselamatan pasien merupakan suatu hal yang penting karena membangun budaya keselamatan pasien merupakan suatu cara untuk membangun program keselamatan pasien secara keseluruhan. World Health Organization (WHO) mengungkapkan bahwa keselamatan pasien merupakan masalah kesehatan masyarakat global yang serius. 


\section{PEMBAHASAN}

Keselamatan pasien dan mutu pelayanan kesehatan yang tinggi adalah tujuan akhir yang selalu diharapkan oleh rumah sakit, manajer, tim penyedia pelayanan kesehatan, pihak jaminan kesehatan, serta pasien, keluarga dan masyarakat.

Di RSU daerah Sumbawa, manajemen keselamatan pasien belum berjalan dengan baik. Fungsi manajemen seperti planning, organizing, actuating, dan controlling terkait keselamatan pasien masih belum dilaksanakan sesuai dengan standar. Fungsi planning atau perencanaan merupakan landasan dari pelaksanaan fungsi manajemen yang lain. Fungsi perencanaan keselamatan pasien di RSU daerah Sumbawa dituangkan dalam perumusan program kerja terkait keselamatan pasien. Programnya mencakup perumusan indikator, penyusunan pedoman kegiatan, program pelatihan dan pengembangan, sosialisasi indikator mutu terkait keselamatan pasien, dan analisa keselamatan pasien. Program kerja yang sudah ditetapkan tentunya membutuhkan suatu strategi pendekatan agar bisa terlaksananya sesuai dengan harapan, sehingga dapat meningkatkan mutu dan budaya keselamatan pasien. Peningkatan nilai budaya keselamatan pasien melalui penerapan pengukuran budaya rutin dengan diseminasi hasil yang luas. Adanya perencanaan tindakan untuk perbaikan yang mencakup tujuan kepemimpinan dan keterlibatan dari semua tingkat staff, dan program keselamatan pasien yang beragam dan juga pendidikan.

Fungsi organizing merupakan suatu strategi untuk melaksanakan program keselamatan pasien. dampak beberapa strategi peningkatan budaya keselamatan pasien, menunjukkan bahwa bukti kuat yang mendukung praktek-praktek terbaik dalam peningkatan budaya keselamatan. Penyelenggaraan training bagi manajer dan semua tugas/staf sangat penting dalam meningkatkan pemahaman, sehingga kesadaran terkait peran masing-masing dapat dijalankan sesuai dengan standar keselamatan pasien. Intervensi pelatihan bermanfaat dalam meningkatkan persepsi, sikap dan kesadaran petugas terkait budaya keselamatan, sehingga menurunkan jumlah kejadian yang merugikan dan meningkatkan keselamatan pasien.

Departemen Kesehatan Republik Indonesia menetapkan lima isu penting terkait keselamatan di rumah sakit, yaitu patient safety, keselamatan pekerja, keselamatan bangunan dan peralatan di rumah sakit yang bisa berdampak terhadap patient safety dan petugas, keselamatan lingkungan yang berdampak terhadap pencemaran lingkungan dan keselamatan bisnis rumah sakit yang terkait dengan kelangsungan hidup rumah sakit. Manajemen patient safety memegang peranan sangat penting dalam peningkatan mutu pelayanan kesehatan. 
Patient Safety merupakan upaya-upaya pelayanan yang mengutamakan keselamatan pasien. Berdasarkan UU No. 1691/MENKES/PER/VIII/2011 tentang patient safety pihak rumah sakit diharuskan melakukan kegiatan pelayanan dengan lebih mengutamakan patient safety. Kurangnya kesadaran dan kepedulian akan pentingnya patient safety akan mengakibatkan kerugian bagi pihak rumah sakit dan juga pasien seperti bertambah lamanya pasien dirawat yang akan berdampak pada semakin besarnya biaya yang harus ditanggung dan terjadinya resistensi obat. Mencegah dampak pasien terhadap KTD terkait kematian dan ketidakmampuan yang menetap sangat erat kaitannya dengan kinerja perawat dalam lingkup penerapan patient safety. Considine mengatakan bahwa untuk mencegah KTD beserta dampaknya yaitu dengan peningkatan kemampuan perawat terkait pencegahan dini, deteksi risiko serta koreksi terhadap abnormalitas yang mungkin bisa terjadi pada pasien. Schoonhoven, Grobbee, Bousema dan Buskens berpendapat bahwa ketidakseragaman persepsi terkait deteksi risiko terhadap pasien akan mengakibatkan pressure ulcer berdasarkan temuan data sebesar 70\%. Dengan demikian KTD dapat diturunkan dengan penerapan patient safety yang baik. Upaya untuk membangun budaya keselamatan pasien (culture of safety) disokong oleh tiga pilar yaitu teknologi, proses, dan SDM sebagai pilar dari pondasi perawatan pasien secara aman. Program keselamatan pasien mulai dari perencanaan hingga evaluasi menjadi wewenang tim keselamatan pasien rumah sakit.

Obat-obatan yang sering disebutkan dalam isu keselamatan pasien adalah pemberian elektrolit konsentrat secara tidak sengaja. Berbagai isu yang terjadi dalam lingkup keperawatan dan pelayanan kesehatan menuntut tingkat manajerial keperawatan memperbaiki lingkungan pekerjaan perawat, meningkatkan retensi perawat, dan meningkatkan kepuasan perawat, sehingga akan mempunyai dampak positif dalam kualitas pelayanan kesehatan yang diberikan. Kepuasan perawat terhadap lingkungan pekerjaannya dihubungkan dengan pemberdayaan psikologis dan pemberdayaan struktural di tempat kerja. Pemberdayaan struktural di tempat kerja akan meningkatkan kepuasan perawat, efikasi diri perawat, produktivitas dan keefektifan pekerjaan perawat. Persepsi perawat mengenai prosedur keselamatan pasien dan otonomi Di tempat kerja merupakan faktor yang berpengaruh terhadap kepuasan kerja perawat. Kualitas pelayanan yang diberikan kepada pasien dipengaruhi secara kuat oleh budaya yang diciptakan dalam rumah sakit dan dikembangkan melalui organisasinya menyatakan bahwa terdapat korelasi yang kuat antara budaya keselamatan pasien di rumah sakit dengan peningkatan keselamatan pasien. 
Keselamatan pasien (patient safety) merupakan isu global dan nasional bagi rumah sakit, komponen penting dari mutu layanan kesehatan, prinsip dasar dari pelayanan pasien dan komponen kritis dari manajemen mutu. Dalam lingkup nasional, sejak bulan Agustus 2005, Menteri Kesehatan RI telah mencanangkan Gerakan Nasional Keselamatan Pasien (GNKP) Rumah Sakit, selanjutnya Komite Akreditasi Rumah Sakit (KARS) Depkes RI telah pula menyusun Standar Keselamatan Pasien Rumah Sakit yang dimasukkan ke dalam instrumen akreditasi RS di Indonesia. Patient Safety merupakan suatu variabel untuk mengukur dan menilai kualitas pelayanan suatu asuhan yang berdampak terhadap pelayanan kesehatan.

Kejadian Tidak Diharapkan atau KTD sering terjadi pada pasien saat mendapatkan perawatan di rumah sakit, sehingga kejadian tersebut sangat merugikan bagi pasien tersebut juga bagi rumah sakit sendiri. KTD bisa terjadi karena berbagai faktor diantaranya beban kerja perawat yang berat, komunikasi yang kurang tepat, penggunaan Alat dan sarana yang kurang tepat bisa memicu terjadinya patient safety. Rumah Sakit dapat melakukan 7 upaya khusus untuk menjaga keselamatan pasien, seperti membangun kesadaran akan nilai keselamatan pasien, memberi arahan dan dukungan pada tenaga kesehatan, mengintegrasikan aktivitas resiko, mengembangkan sistem pelaporan, selalu melibatkan dan berkomunikasi dengan pasien, belajar dan berbagi pengalaman tenaga kesehatan pasien, mencegah cedera melalui implementasi sistem keselamatan pasien. Mutu pelayanandi rumah sakit juga dipengaruhi oleh mutu pelayanan keperawatan Karena pelayanan keperawatan merupakan bagian integral dari pelayanan kesehatan. Jaminan mutu suatu pelayanan kesehatan salah satunya dengan meningkatkan keselamatan pasien, mengurangi kejadian infeksi nosokomial, resiko jatuh, dan resiko cedera karena kelalaian dari petugas kesehatan itu sendiri. Aspek yang termasuk ke dalam mutu pelayanan kesehatan adalah keselamatan pasien atau patient safety. Mengingat pentingnya patient safety dan menjadi suatu tuntutan masyarakat dalam melaksanakan program keselamatan pasien di rumah sakit, maka diperlukan sebuah acuan yang jelas untuk melaksanakan patient safety tersebut.

Tenaga kesehatan secara umum merupakan satu kesatuan yang saling terikat terdiri dari tenaga medis, tenaga perawat, tenaga paramedis non perawatan dan tenaga non medis. Dari semua kategori tenaga kesehatan tersebut, tenaga perawat merupakan tenaga kesehatan yang kontak langsung atau berinteraksi langsung dengan pasien, sehingga mereka memiliki peranan penting dalam menentukan baik buruknya suatu pelayanan kesehatan. Faktor yang mempengaruhi insiden patient safety adalah kinerja dari individu tenaga kesehatan itu sendiri. Peran perawat dalam memberikan asuhan keperawatan kepada pasien sangat penting untuk 
diperhatikan, harus sesuai dengan sistem penanganan pasien yang telah ditetapkan masingmasing rumah sakit. Pengetahuan perawat tentang patient safety terdiri dari mengetahui definisi dan indikator patient safety, melakukan pencegahan, dan pelaporan ada tidaknya tindak Kejadian Tidak Diharapkan (KTD).

Standar Keselamatan Pasien tersebut terdiri dari tujuh standar yaitu :

1. Hak pasien

2. Mendidik pasien dan keluarga

3. Keselamatan pasien dan kesinambungan pelayanan

4. Penggunaan metode-metode peningkatan kinerja untuk melakukan evaluasi dan program peningkatan keselamatan pasien

5. Peran kepemimpinan dalam meningkatkan keselamatan pasien

6. Mendidik staf tentang keselamatan pasien

7. komunikasi merupakan kunci bagi staf untuk mencapai keselamatan pasien

\section{PENUTUP}

Isu Keselamatan Pasien atau patient safety merupakan salah satu isu yang dibahas dalam pelayanan kesehatan. Perawat merupakan tenaga kesehatan yang terdekat dan selalu berinteraksi dengan pasien dalam memberikan asuhan keperawatan dan harus sesuai dengan sistem penanganan pasien. Selain perawat dan tenaga medis lain, mahasiswa praktikan atau mahasiswa profesi ikut berperan tentang terlaksananya patient safety di rumah sakit. Salah satu faktor yang mempengaruhi perawat dalam tindakan keperawatan untuk mengambil keputusan yang logis dan akurat adalah pengetahuan perawat. Dasar pengetahuan perawat yang baik berhubungan dengan Asuhan Keperawatan yang aman. Peningkatan pengetahuan perawat tentang patient safety akan berdampak pada peningkatan kualitas pelayanan keperawatan. Patient Safety (Keselamatan Pasien) adalah pasien bebas dari haram (cedera) yang termasuk di dalamnya adalah penyakit, cedera fisik, psikologis, sosial, penderitaan, cacat, kematian, dan lain-lain yang seharusnya tidak seharusnya terjadi atau Cedera yang potensial, terkait dengan pelayanan kesehatan.

\section{REFERENSI}

1. Bawafaa, E.., Wong, CA..,\& Laschinger,H.2015. The Influence Of Resonant Leadership on the Structural Empowerment and job Satisfaction of registered nurses. Journal of Research In Nursing. Vol: 20(7).610-622. 
2. Hakim,Lukman, Widodo J.Pudjirahardjo.2014. Optimalisasi Proses Koordinasi Program Keselamatan Pasien (Patient Safety) Di Rumah Sakit X Surabaya. Jurnal Administrasi Kesehatan Indonesia. Vol: 2(3).198-208.

3. Heriyati, Muhammad Fauzar Al-Hijrah, Masniati.2019. Budaya Keselamatan Pasien Rumah Sakit Umum Daerah Maneje. Jurnal Kesehatan. Vol: 2(3).194-205.

4. Juniarti, Nanda Hani, Ahmad Ahid Mudayana.2018. Penerapan Standar Keselamatan Pasien di Rumah Sakit Umum Daerah Provinsi Nusa Tenggara Barat. Jurnal Kesehatan Poltekkes Ternate. Vol: 11(2).93-108.

5. Rosita Jayanti Bardan.2017. Analisis Penerapan Keselamatan Pasien di Rumah Sakit Umum Daerah INCHE ABDOEL MOEIS Tahun 2017. Tesis. Magister Administrasi Rumah Sakit Fakultas Kesehatan Masyarakat Universitas Hasanuddin Makassar.

6. Simamora, R.H.,\& Nurmaini,C.T.S.(2019). Knowledge of Nurses about Preventiont of Patient Fall Risk in Inpatient Room of Private Hospital in Medan. Indian Journal of Public Health Research \& Development,10(10).759-763.

7. Sulahyuningsih, Evie, Didik Tamtomo, Hermanu Joebagio.2017. Analysis of Patient Safety Management in Committee for Quality Improvement and Patient Safety at Sumbawa Hospital, West Nusa Tenggara. Journal of Health Policy and Management. Vol: 2(2).147-156.

8. Sumami.2017. Analisis Implementasi Patient Safety terkait Peningkatan Mutu Pelayanan Kesehatan di Rumah Sakit. Jurnal Ners dan Kebidanan Indonesia. Vol: 5(2).91-99.

9. Tanti Arini.2018. Budaya Keselamatan Pasien berbasis Pemberdayaan Struktural dengan Kepuasan Kerja Perawat. Tesis. Program Studi Magister Keperawatan Fakultas Keperawatan Universitas Airlangga Surabaya.

10. Triwibowo,Cecep, Sulhah Yuliawati, Nur Amri Husna.2016. Handover Sebagai Upaya Peningkatan Keselamatan Pasien (patient safety) di Rumah Sakit. Jurnal Keperawatan Soedirman. Vol: 11(2).76-80.

11. Utarini,Adi, Hanevi Djasri.2012. Keselamatan Pasien dan Mutu Pelayanan Kesehatan: Menuju kemana?. Jurnal Manajemen Pelayanan Kesehatan. Vol: 15(4).159-160.

12. Yusuf, Muhammad.2017. Penerapan Patient Safety Di Ruang Rawat Inap Rumah Sakit Umum Daerah Dr. Zainoel Abidin. Jurnal Ilmu Keperawatan. Vol: 5(1).84-89. 